\title{
THE DEVELOPMENT OF THE TEETH, AND SOME OF THE CONTESTED POINTS IN REGARD TO THEIR DEVELOPMENT AND STRUCTURE ${ }^{1}$
}

\author{
ROBER'T R. ANDREWS \\ Cambridge, Massachusetts \\ CONTENTS
}

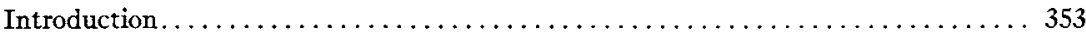

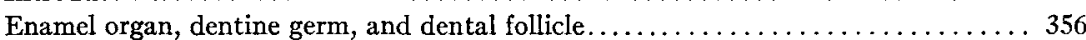

Dentine germ ........................................... 357

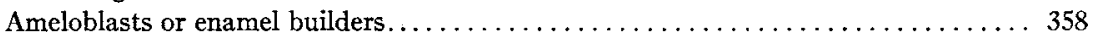

Odontoblasts, the dentinal matrix-forming cells ................... 361

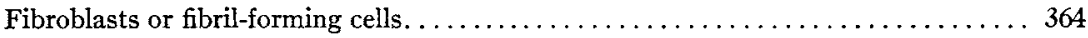

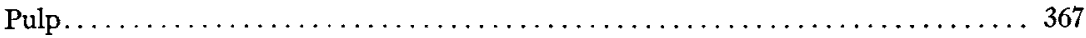

Cementum ................................................ 367

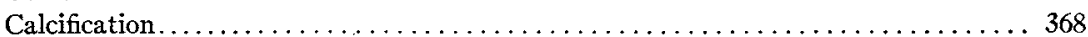

Membranes............................................. 373

"Sheath of Neumann"....................................... 374

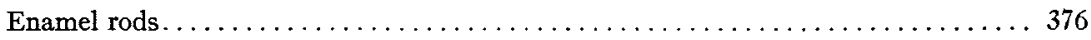

Penetrating fibers in the enamel................................. 377

So-called granular layer of Purkinji and of Tomes.................... 381

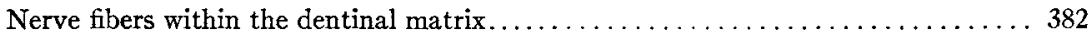

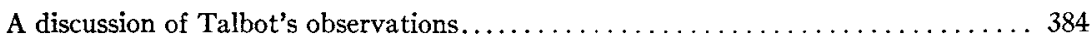

\section{INTRODUCTION}

It is a great pleasure for me to present to the American Academy tonight some of the results of my many years of work in dental research. I shall find it necessary to quote somewhat from former papers. I propose to discuss some of the contested points in regard to developmental processes in teeth, as well as to the structure of the finished tooth.

I doubt if any of the fellows of the Academy with us tonight were present at a meeting held in the rooms of the Medical Library Asso-

1 Presented to the American Academy of Dental Science, at a meeting in Boston, February 5,1919. See page lxxxvi of the section on Proceedings of Dental and Stomatological Societies. 
ciation thirty-one years ago, when I read my first paper, on the calcification of enamel. Later, in 1890, after some further investigation, I read practically the same paper before the International Medical Congress, at the University of Berlin. At this meeting I was most ably assisted at the lantern by the late Professor W. D. Miller, who illustrated my paper with the first electric lantern that had ever been used in public. I had taken my case of sections of the actual tissues with me, to verify the photographs, if there should have been any question as to their true reproduction of the actual tissues. I was fortunate in this, because Professor Miller used the sections of the actual tissues to illustrate my paper, instead of the photographs I had so carefully prepared. The pictures were shown very clearly on the screen and they verified, without question, the conclusions of my paper. It was seen that the enamel rods were not formed by the elongation and calcification of the enamel cells, as was taught by the authorities, and the text books, of that time, but were formed by minute globular bodies-calco-spherites-that were forming and being deposited at the dentinal end of the ameloblast, whereby, merging or coalescing, they formed the typical globule, which, when calcified, formed one of the segments of the enamel rod.

The method I used in the preparation of tissue in those early days was extremely simple. My endeavor was to prepare and cut my sections as near to the life of the embryo as I could. I used human embryos when I could procure them, but more often used the embryos of pigs, cows, sheep, dogs and cats. The various processes of formation are practically the same in all of these kinds of embryos. When I wished to prepare tissue, I procured embryos at, or nearly at, the time of birth; and, while they were still fresh and moist, I placed the jaws in a 0.5 per cent solution of chromic acid, changing it three times daily for three or four days. The edges of the calcified tissue were then found to be sufficiently decalcified for the preparation of a number of thin sections. I first washed the tissue in distilled water, and then placed it in a solution of gum-arabic for several hours to make the tissue firm. Alcohol was carefully used to take out the water and the tissue was then embedded in a preparation of paraffin and lard, which had been poured into a convenient mould. When cool it was ready for section cutting. 
The microtome which I used had this important advantage over others: the tissue and knife were both under fluid when the sections were cut; and, as they were cut, they floated off and remained in the fluid until they were taken up for examination. I cut until the tissue that had not been decalcified was reached, and then each cutting dulled the edge of my knife; but I had the satisfaction of getting good sections, and of working as near to life as I could. After cutting, the sections were carefully examined, and those which I thought worth keeping were placed in distilled water for a short time, to dis-

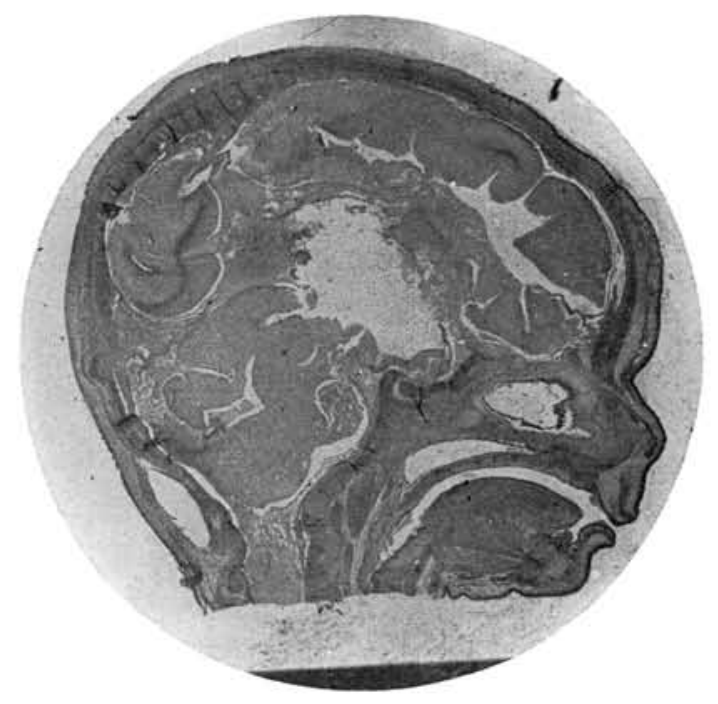

Fig. 1. Section of Head of Human Embryo (Low Power)

The "powers" referred to in the legends for the figures in this paper were the following: "Low power" -an inch-and-a-half objective, or a quarter-inch objective; " high power" - a very fine Zeiss twelfth-inch objective, oil immersion.

solve out the remaining gum, and then were mounted in glycerin jelly. By using this simple method, I prevented shrinking or shrivelling of the tissue - tissues are shrunken and shrivelled when they are kept for a long time in reagents such as acids, alcohols, oil of cloves, and other preparing fluids, or by the drying process which prepares them for the serial sections that I have seen cut by the Thoma microtome. 
ENAMEL ORGAN, DENTINE GERM AND DENTAL FOLLICLE

The enamel organ, at its first stage, is a club-shaped ingrowth from the malpighian layer of the epithelium into the connective tissue which surrounds it. This appears at about the forty-eighth day of embryonic life. As it forces its way by growth into the connective tissue, it expands at its base, and the cells within are multiplying and differentiating, rapidly assuming a stellate form, and causing an expansion at the base of the organ. As it enlarges, it enfolds the

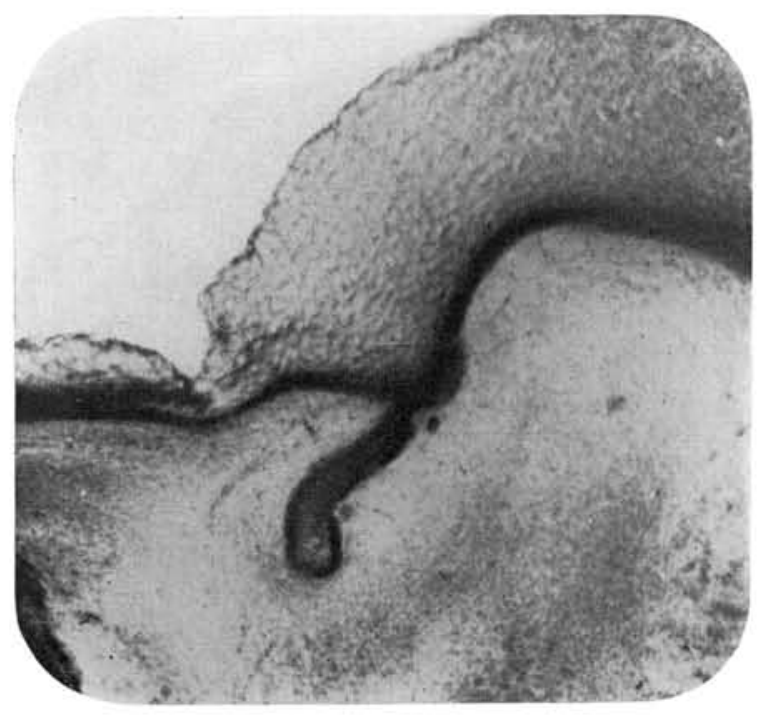

Fig. 2. Enamel Organ, First Stage of Growth (Low Power)

growing dentine germ, which it will cover on all sides except its base and will form a cap or bell-shaped organ over it (figs. 2 and 3).

In making a section of the enamel organ at this time, we find that the cells on the periphery of the organ are columnar in form-the columns of cells next the dentine germ are to be the ameloblasts or enamel builders, the internal layer; while those on the outer surface, the external layer, have as yet no known function. Just within the internal and external layers is seen a layer of cells, resembling con- 
nective tissue, but of epithelial origin. This is a layer called the stratum intermedium. This stratum is an important layer, appearing to give out new cells to the forming enamel, and also to the cement substance which surrounds the rods. The stellate reticulum, a mass of cells filling the central portion of the enamel organ, is thought to be of slight importance. It probably supplies the salts of lime to the ameloblasts at the beginning of calcification; but when calcification is actively going on, all of this tissue disappears at that part.

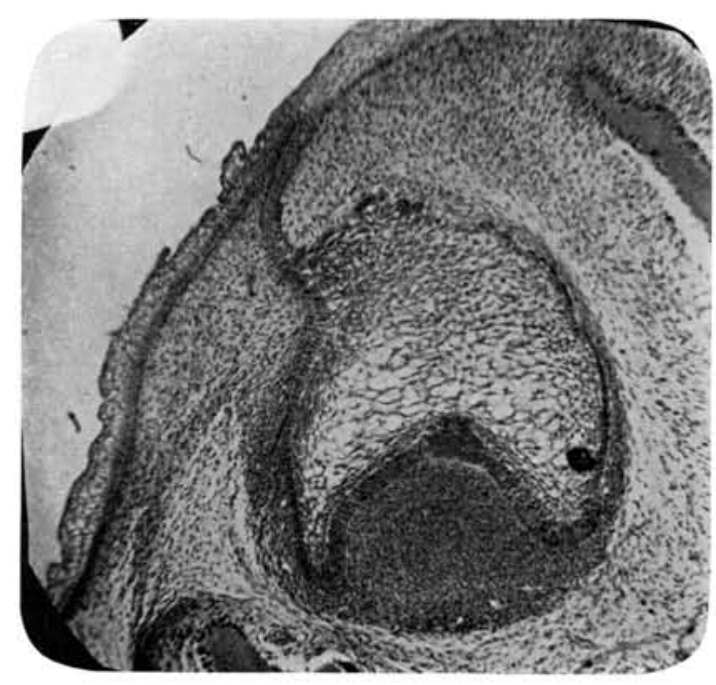

Fig. 3. Enamel Organ and Dentine Germ, Showing the Different Layers (Low POWER)

DENTINE GERM

At about the end of the second and the beginning of the third month of intrauterine life, in the embryonic tissue of the jaw, we find the primary specialization of cells which are to form the dentine germ and from which come the cells that afterward form the dental pulp. It is in no special zone or layer of this connective tissue that the dentine germ is formed, but the formation seems wholly influenced by contact with an enamel organ. In the presence of this organ, the connective tissue cells become stimulated and active. It would 
appear that they offered resistance to further ingrowth of the dentine germ, and from this resistance the enamel organ was made to surround it. The stimulation and activity of the cells is shown by their rapid growth, which clouds the part at this point, becoming a dense focus of new growth. The tissue is seen to be actively building itself up, and this results in the formation of a papilla, around which the enamel organ is growing like a cap or helmet. The papilla grows to a cusp or cusps, and becomes the dentine germ.

At the end of the third and the beginning of the fourth month, the dentine germ is rather a homogeneous structure; round cells are very numerous; they have relatively large nuclei and nucleoli. As the germ assumes the cusp shape, multiplication of cells takes place around the blood vessels, which have formed in the germ, and after this, a jelly-like or hyaline layer, an exudate, forms around its outer surface. The dentine germ will grow into the depressions of its special enamel organ, an incisor, bicuspid, or molar tooth, and these growths will become the dentine cusps.

When the enamel organ caps the forming dentine germ, we notice that the embryonic connective tissue, starting from near the base on each side of the dentine germ, is forming two layers, which are enclosing the enamel organ and dentine germ. This enclosing tissue resembles a vascular membrane, composed of a network of the embryonic tissue cells, with numerous fine fibers within their walls. At this stage it is forming the dental saculus. The two layers soon completely enclose the enamel organ and the dentine germ, and, as this process is completed, and the organ and germ are within the sac, the latter becomes the dental follicle. Within this closed follicle are the cells which, by multiplying and differentiating, and becoming specialized, shall build up the enamel, the dentine, the pulp, and the cementum of the fully formed tooth (fig. 4).

\section{AMELOBLASTS OR ENAMEL BUILDERS}

As the enamel organ forms over the papilla which is to be the dental germ, the cells covering the germ, named the internal epithelium of the enamel organ, become the ameloblasts or enamel builders. They are now undergoing histological differentiation-they have 


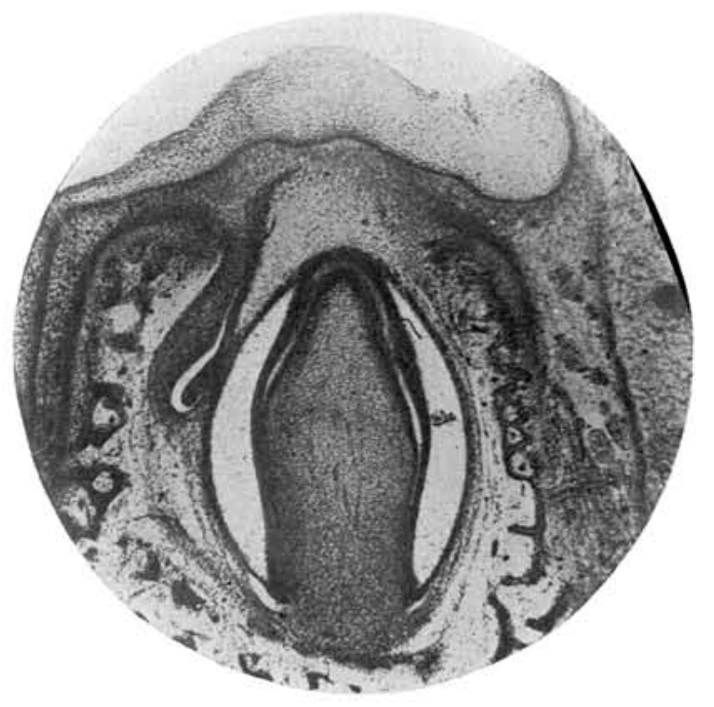

Fig. 4. Dental Follicle, Showing the Bud of the Permanent Enamel Organ in THE Process of Formation (Low Power)

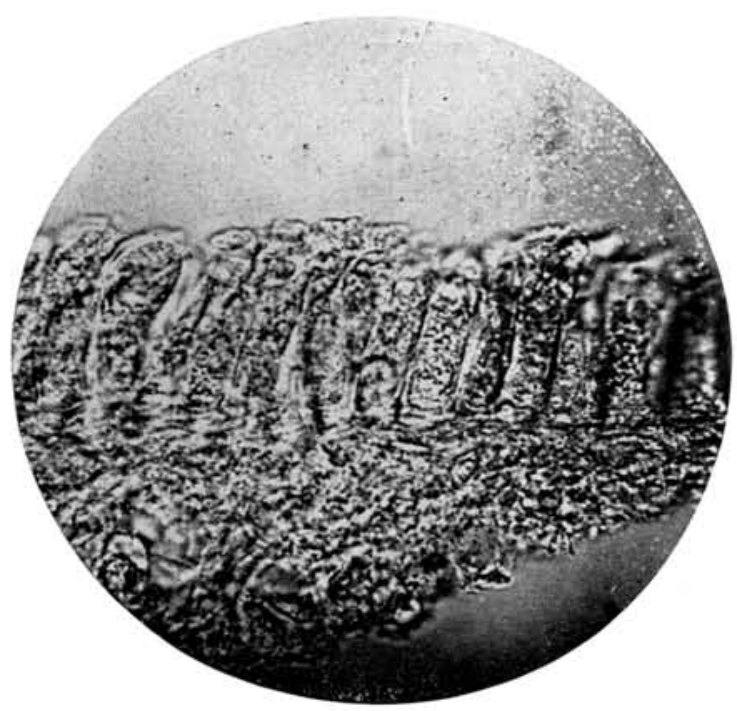

Fig. 5. Layer of Unshrunken Enamel Cells (Ameloblasts) Filled with CalcoSPHERITES (High PoWer) 
grown from epithelial elements to columns or masses of protoplasm. A marked change has taken place within them. As builders of a calcified structure, they differ from the surrounding cells: by a peculiar metamorphosis they have become specialized. They now become a physiological apparatus, a sort of chemical laboratory, if you please. In this condition they are unlike other cells, being unable to lead an independent existence. These builders of the enamel do not seem to have any membrane. The power of the cytoplasm of these cells, with its formative activity, creates, with lime from the blood, minute globular bodies. These are plainly seen to differ from the cytoplasm, by which they are placed so that they occupy a definite position of fixed form and structure (fig. 5). Thus it is seen that the special function of these cells is to absorb the calcific material from the blood. Within the cells this calcific material is elaborated, and is given out, on the calcifying dentine, in an altered form. The calcareous matrix is not formed out of the protoplasmic substance alone; this protoplasmic substance plays the part of an intermediary, selecting its earthy matter from its environment.

In that portion of the ameloblast farthest away from the calcifying enamel, calcific matter is being elaborated by lime mingling with the protoplasmic fluids. It is in such fine subdivisions that it is not often visible, even with the highest powers of the microscope. A little lower in the region of the nucleus we have an ocular demonstration of it in the form of minute globules of calcific matter. These have been named calco-spherites. They appear to enlarge, not by growth, but by a process of coalescing, becoming larger as they are conveyed by the living matter of the cell to the region of the calcifying enamel. Here they are found to have coalesced into their typical form, very nearly of uniform size. As the enamel globules are placed near the point of calcification, they are found to be somewhat larger than the rod they are to form. By some power they seem forced inward against the portion calcified, as if undergoing some sort of compression.

When the process of enamel calcification is about to take place, we find that the connective tissue, with its rich network of capillaries, has come into close proximity with the upper ends of the ameloblasts, the spindle-shaped layer of cells-the stratum intermedium-being between them. The external epithelium of the enamel organ and the 
cells of the stellate reticulum are not now to be seen-although one may see a trace of them, they seem to have been absorbed. The spindle-shaped cells of the stratum intermedium remain. By some authors they are credited with being connective tissue cells, but they are of epithelium origin. The ameloblasts, at this stage, strongly resemble gland cells, forming a layer of columnar cells over the already calcifying dental cusp.

The process of calcification within the enamel cell is a difficult problem for the dental histologist to unravel. The tissue which is under his microscope is dead tissue, and the processes which take place during life have ceased. We see only that stage of growth and action which has taken place before the microtome cut the section, after the death of the tissue. Another section, cut during a different stage of cell activity, will give a different picture corresponding to its period of life. If the layer of enamel cells is pulled away from the cap of formed dentine, we shall see that the cap of dentine is everywhere covered with quite regularly formed globular bodies ( $f g .6$. $)$. If on the other hand, the layer of enamel cells is against the formed cap of dentine, the calco-spherites are blending and forming block-like columns of globules, as though taking the form of the future enamel rod (fig. 7). They appear to be in a gelatinous substance which is between the dentine and the enamel cells, and here, by an unknown chemic hardening process, they become the hardened columns of the enamel, as I demonstrated at Berlin, in 1890. The enamel rods are thus built up, globule on globule, until the rods are complete. New ameloblasts from the cells of the stratum intermedium are produced to supply those necessary to cover the larger circumference of the surface as it forms, the tissue calcifies, and thus normal enamel is made.

\section{ODONTOBLASTS, THE DENTINAL MATRIX-FORMING CELLS}

In his work on "The cell in development and inheritance," Wilson states that the term "cell" is a biological misnomer, for whatever the living cell is, it is not, as the word implies, a hollow chamber surrounded by walls. The definition of Max Schultz that a cell is a mass of protoplasm, containing a nucleus, would apply to the toothforming cells much better, for these cells are merely masses of proto- 


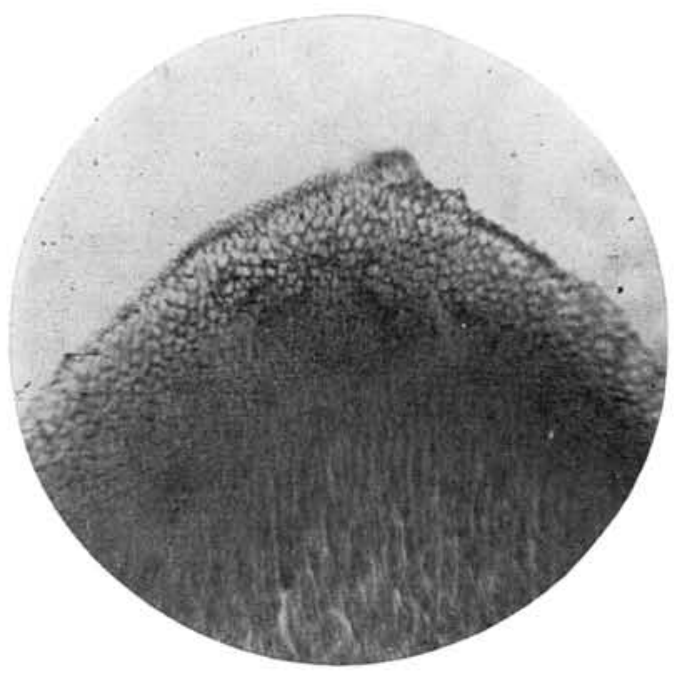

Fig. 6. Enamel Globules on the Dental Cusp, Deposited by Ameloblasts (High POWER)

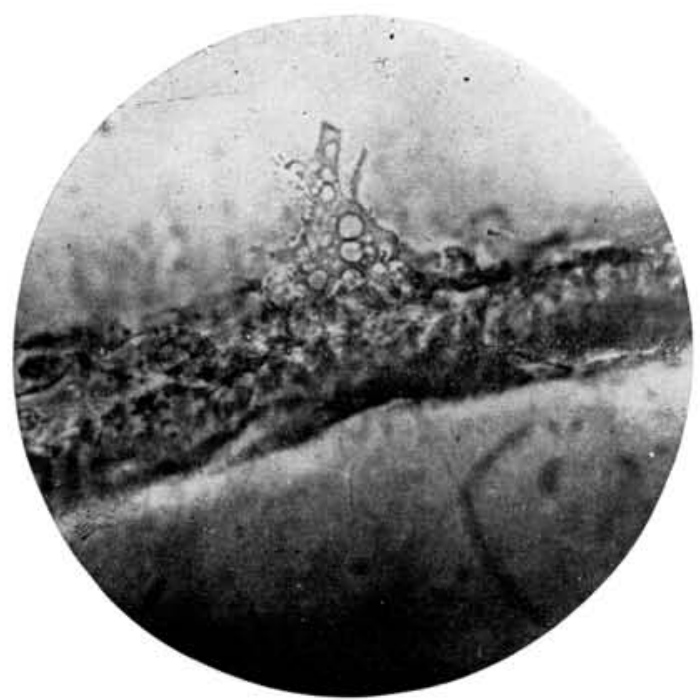

Fig. 7. Globules in the Process of Forming Enamel Rods (High Power) 
plasm, each containing its nucleus, that have been given their prismatic or columnar form by the mechanical pressure of surrounding structures, or by unequal growth and differentiation, or by active movements of the cell substance itself. The word cell, however, has become fixed in scientific nomenclature, and efforts to replace it by a better name have failed.

The round cells around the rim of the dentine papilla appear to be in or against a protoplasmic substance, an exudate, sometimes called a zone of amorphous material. It is a hyalin layer on the outermost surface of the germ. The cells just within become richer in protoplasm, and many processes are seen to be forming from them. They are becoming branched cells; a little later the cells at the surface grow larger and assume a columnar shape, which may be caused by mechanical compression. We also see just within this layer of cells some that are pear-shaped, conical, cylindrical, or spindle-shaped. Some authorities have spoken of what they call elementary cells on the outer layers, and from which they say the odontoblasts are formed; but I have never observed anything but globular masses that are not cells, which are found in the protoplasmic substance of the hyaline rim spoken of above. At the beginning of the fifth month these cells on the surface are seen to be undergoing a histologic differentiation, as stated above, and are becoming specialized or formative cells, the odontoblasts. They are membraneless and little more than masses of protoplasm, which are seen to be filled, as calcification commences, with great numbers of bright, glistening globules of different sizes. At this time dentification is about to begin. How does this process of calcification take place? This we do not wholly understand, nor do we understand the chemical or physical properties of the building materials. At this time a blood supply is evident, and at the seventh month there is a perfect vascular system consisting of arteries, veins and capillary network.

As I have said, the details of the vascular mechanism by which the odontoblasts are supplied with lime necessary to form calcified structure have not as yet been clearly worked out. Capillaries near the formative cells do not communicate directly with the cells, and must therefore pass the lime through the intracellular substance. The inorganic calcium which is necessary, manifestly cannot be supplied as such by the organic formative cells, but must make its initial 
entrance into the body from without. This entrance in the fetal state must necessarily be through the maternal circulation, and after birth it must come from the food which passes through the alimentary canal. From here it must be carried to the specialized formative cells which superintend the process of calcification, and there is but one such distributor, which is the blood supply.

FIBROBIASTS OR FIBRIL-FORMING CELLS

The study of many sections of the pulp of fully formed teeth has led me to believe that the pear-shaped cells fringing the outer surface of the pulp, and having fibers running into the canals of the dentine matrix, are not cells having the same functions as those of the matrix formative cells, or odontoblasts, which are square and abrupt against the dentine matrix while it is forming. There are indications that the pear-shaped fiber cells have a delicate membrane and that they remain pear-shaped, larger or smaller, throughout the vitality of the pulp. As the dentine layer forms, the fiber of the fiber cell lengthens; and, against the surface or sides of this lengthening fiber in the dentine matrix, the same hyalin layer is left uncalcified as is found against the forming matrix next the formative pulp, and becomes the so-called sheath tissue. We frequently see two fiber cells merged into one, caused by the lessening circumference of the forming dentine; they have merged, one losing its identity completely at that point. It appears as though all the branching and lengthening of the fibers must be from the merging of these fiber cells ( figs. 8 to 11 , inclusive).

I am led to believe this cell, which I have named the fibroblast, has an important function to perform, a vital function during the life of the pulp, superintending the supply of nourishment from the pulp to the dentine matrix, through its canals and their anastomosing branches. Authorities today tell you that the odontoblasts send their fibers into the dentine matrix. I believe they are in error. I am convinced that the odontoblasts are matrix builders only. The fibroblasts are (in properly prepared sections) seen to be wedged between the odontoblasts; and their one, two, or three fibers pass between, and through, the membraneless odontoblast. I called the attention of the profession, in 1886 , to the important function of the fibroblast. 


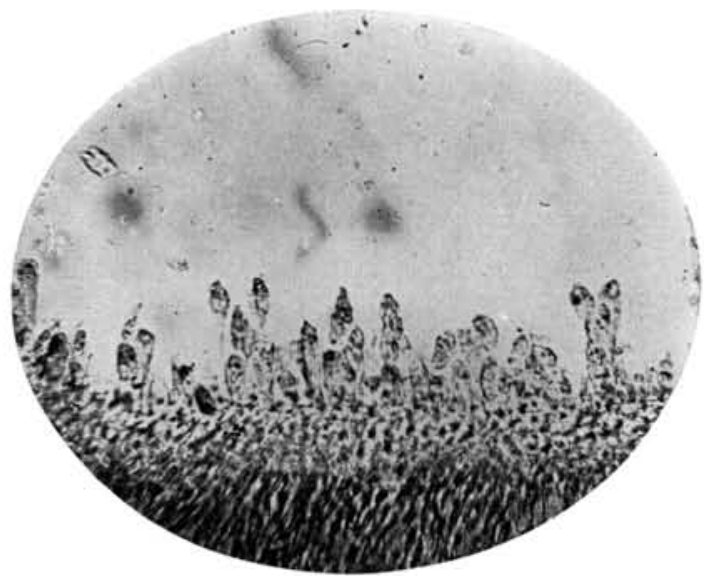

Fig. 8. Fibroblasts: Pear-Shaped Fiber-Forming Cells Seen between the Odontoblastic Layers (Low POWER)

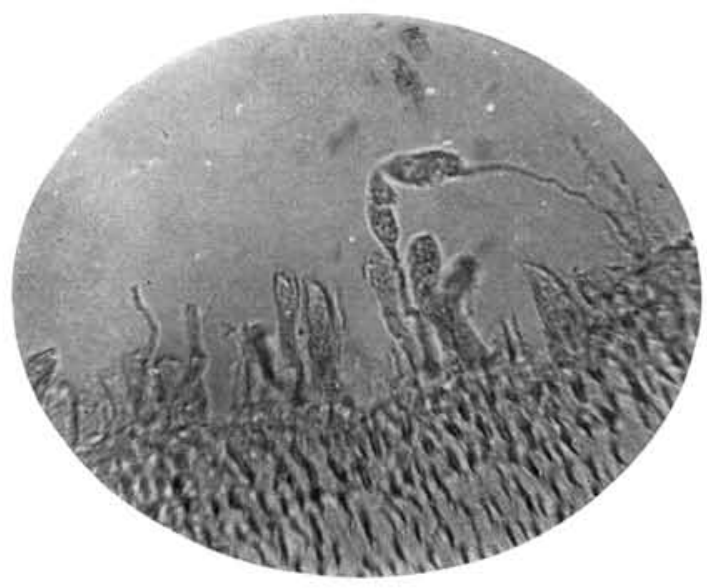

Fig. 9. Fiber-Forming Cells and Odontoblasts (High Power 


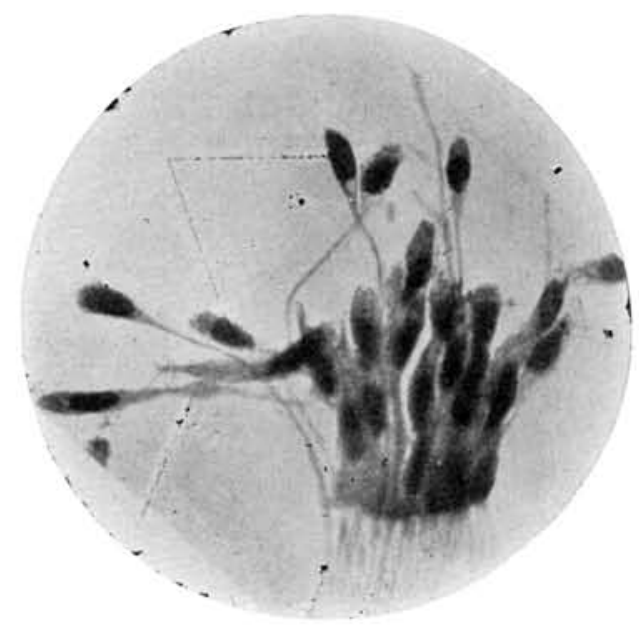

Fig. 10. Fiber-Forming Celles (from a Photomicrograph Taken by Professor Hanazawa: High Power)

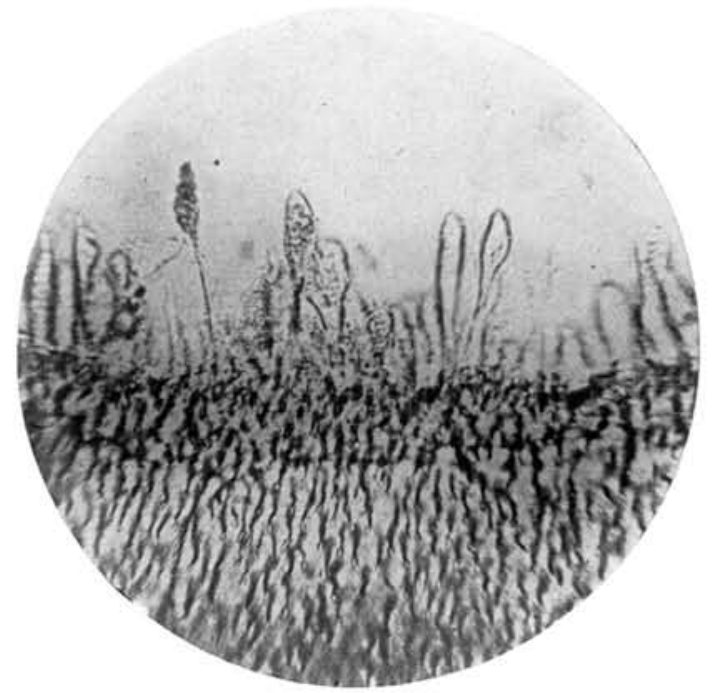

F.g. 11. Fibroblasts: Fiber-Forming Cells (High Power) 
PULP

The pulp tissue is shown to be a continuation of the alveolar periostium, and is composed of a vast number of branched cells, each having a nucleus. Within the pulp substance of the developing tooth, the connective tissue cells are scant, showing a large nucleus and many branched connecting processes. By anastomosing, one with another, they form a reticulum of fine fibers. Spherical lymphoid corpuscles may also be found in the tissue of the dental pulp. At the periphery of the pulp are two distinct strata, of different cells. The outermost, next the forming dentine, are the columnar odontoblasts, or dentine-matrix builders; next, within these, are to be seen the pear-shaped cells.

The fibroblasts, with their long fibers passing between and through the membraneless odontoblasts, enter the canal in the forming matrix of the dentine. A dense network of nerve fibers and capillaries is to be found near these builders of the dentine. In the central portion of the pulp, the spindle-shaped cells, already spoken of, make up the main mass of the dental pulp tissue.

\section{CEMENTUM}

The cementum has its origin from the cells of the inner layer of the dental sacculus. It is an intermembranous bone, which is formed without the intervention of cartilage. This inner layer of the sac consists of connective tissue cells, fibers and blood vessels. The cells next the forming dentine of the root enlarge and become specialized, as the cementoblasts, or cement builders. They are seen to be arranged in long rows against the dentine of the root, and the process of matrix forming seems to be much the same, as in the dentine--an exudate is produced and then there is a globular formation, which calcifies, enclosing specialized cells that do not calcify, but which become the living bone cells or lacunae of the cement. These are usually large and have many processes. This calcifying process also encloses many fibers in the matrix of the cement. They have been named the perforating fibers of Sharpey. The cementum is thus seen to be a more or less laminated bone matrix, containing exceptionally large bone corpuscles, with numerous canaliculi anastomosing with others

THE JOURNAL OF DENTAL RESEARCH, VOL. I, NO. 3 
or with the dentine, through, but not with, the interglobular spaces of the dentine edge near the cementum. The cementum is thickest near the end of the root, and sometimes contains vascular canals.

\section{CALCIFICATION}

I shall attempt to give only a very brief description of the process of calcification. It is a process by which organic tissues become hardened by deposition of salts of lime within their substance. In the intracellular tissue and in the substance of the cells themselves, these salts are deposited in minute particles and in such fine subdivisions that it is difficult to demonstrate many of them even with the higher powers of the microscope. The intercellular substance, either a protoplasmic or gelatinous fluid, or semi-fluid, receives the lime salts. In it the lime changes its chemic nature, uniting with a portion of the organic substance of the cell, or of the layer of exudate, and forming small globular bodies, which are the calco-spherites; and these, blending or coalescing into a perfect flow, form a substance called calco-globulin. This calco-globulin, which is a lifeless substance, has been deposited by the cells, and in some cases into the substance of the cells themselves, where, by a further hardening process, it becomes the fully calcified matrix. It will be noticed that near this point of formation there is always to be found a rich, capillary blood supply, and from this the lime salts are given out.

As I have said, near the forming matrix the tissue is seen to be full of these microscopic, glistening bodies, the minute masses which are often spoken of as granules. The abundance of these globules at the time of the formation of the enamel, dentine, and cementum, and their entire absence at earlier stages, is to me an indication that the globules are a calcifying substance, the matrix-forming calco-spherites; and following up their future confirms this. Many of them are so small as to be scarcely measurable. In tissue that has not been shrunken, they are almost always spherical. The lower part of the enamel cell toward the dentine, and the layer of forming dentine, contains the larger globules. The growth of the matrix once begun takes place by additions of layers of these globules. I am convinced that the larger ones are composed of hundreds of the smaller ones, 
which have coalesced into the main mass. When the process of cal-. cification commences, if our tissue has been carefully prepared so as to avoid shrinking it, we shall see myriads of the calco-spherites in and about the calcifying layer (fig. 12).

The cells of the stratum intermedium and the star-shaped cells of the stellate reticulum are mottled with minute glistening globular bodies. If, at this time, we introduce a drop of acid under the cover glass, we immediately see the bubbling of decomposing carbonate of lime. These lime salts are from the blood supply nearby (fig. 13). They change their chemic nature as they are passed into the substance of the cell, and these cells superintend their formation into enamel rods; that is, they are laid by the cell against the forming rod. Within the substance of the ameloblasts they are seen to be growing larger by the smaller ones coalescing with others. If at this point of their development the layer of enamel cells is pulled away from the cap of formed dentine, we shall see that the cap of dentine is everywhere covered with quite regularly formed globular bodies. If, on the other hand, the layer of enamel cells is against the formed cap of dentine, the masses are seen to be assuming block-like shapes, as though taking the form of the future enamel rod. They appear to be in a gelatinous substance which is between the dentine and the enamel cells, and here, by an unknown chemic hardening process, they become the hardened columns of the enamel.

In dentine the calcifying process goes on in much the same manner. The odontoblast is merely a mass of protoplasm, and appears to have no membrane; as is the case with the ameloblast, it has a nucleus at a point farthest from the calcifying matrix. In forming the dentine matrix, the odontoblast, or the pulp tissue through the odontoblast, gives out a rich gelatinous substance in a layer about as wide as that of the odontoblast cells. Everywhere between the odontoblasts, as Mummery has demonstrated, is found a rich supply of connective tissue cells, whose function appears to be the forming of a net-work of connective tissue fibers into this gelatinous substance, this network seeming to be a scaffolding upon which the calco-spherites, that produce calco-globulin, are to be deposited. Into this layer the odontoblasts are also superintending the placing of the globules that are within them, and which have been given to them by the blood 


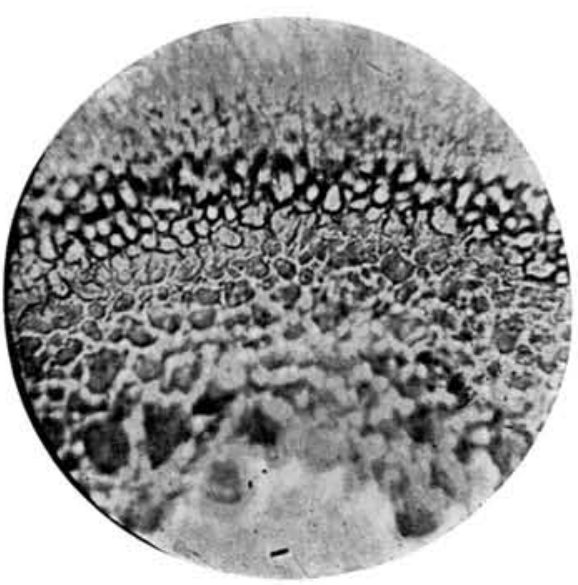

Fig 12. Globular Bodies Forming the First Layer of the Enamel (High Power)

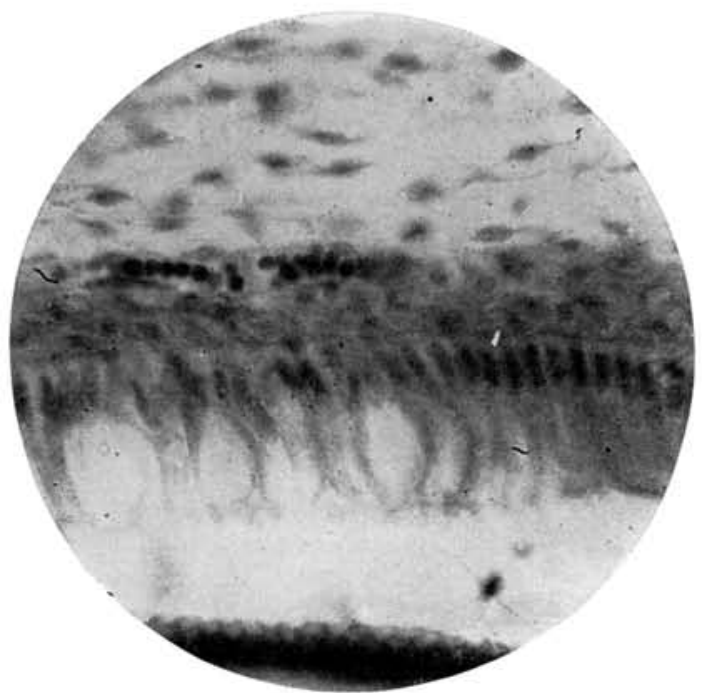

Fig. 13 Blood Supply to the Enamel Cells, Showing Capillary with Blood Corpuscles (High POWer) 
supply found everywhere near their pulp ends. Into the gelatinous substance the globules assemble against the calcified matrix, where, fusing with others, they form a flow, entirely filling the gelatinous substance. This gelatinous substance with its merged mass of globules now becomes calco-globulin. By some natural hardening process it then becomes calcified matrix, and thus another layer of calcified matrix is formed (figs. 14, 15, and 16).

I am convinced that in the cementum, a tissue I have not studied as carefully as I have the others, the calcifying process is much the

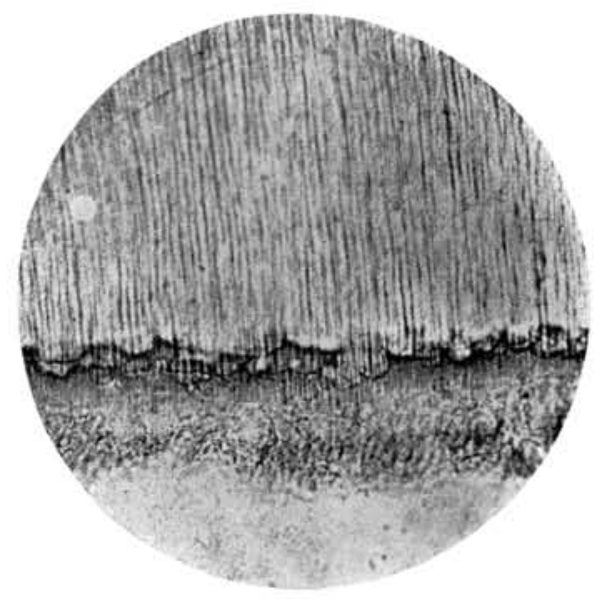

Fig. 14. Globules Forming the Matrix of Dentine (High Power)

same, the connective tissue cells against the forming root become specialized, become cementoblasts. The first cemental calcification takes place by the cementoblasts giving off these globular bodies near the neck of the tooth against the forming dentine of the root, into a gelatinous exudate, this also being given off by the cells. It assumes the form of plates or scales. Afterward the cells themselves are filled with the globules, and appear to lose their identity in the forming matrix; large specialized cells are enclosed in the matrix of the cementum and remain as the living cement cells, or lacunae of the cement. These living cement cells have many processes that anastomose with each other, and into the dentine through the interglobular layer. 


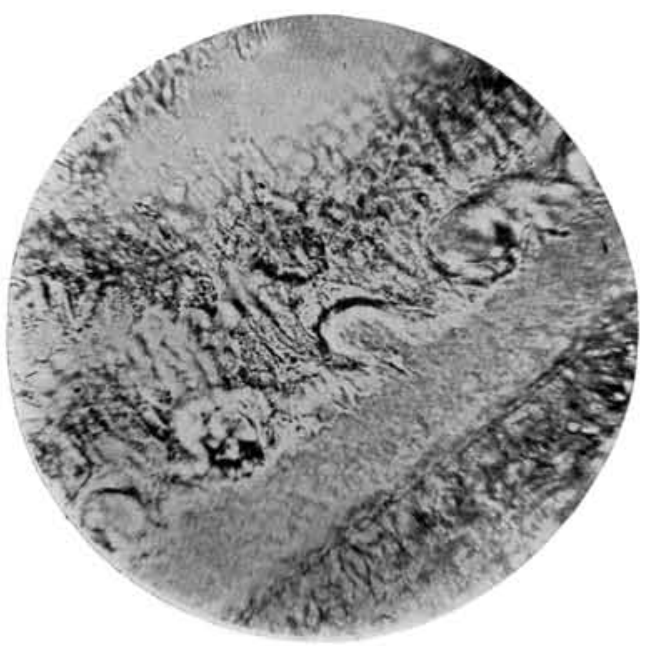

Fig. 15. New Layer of Dentine in the Process of Formation (High Power)

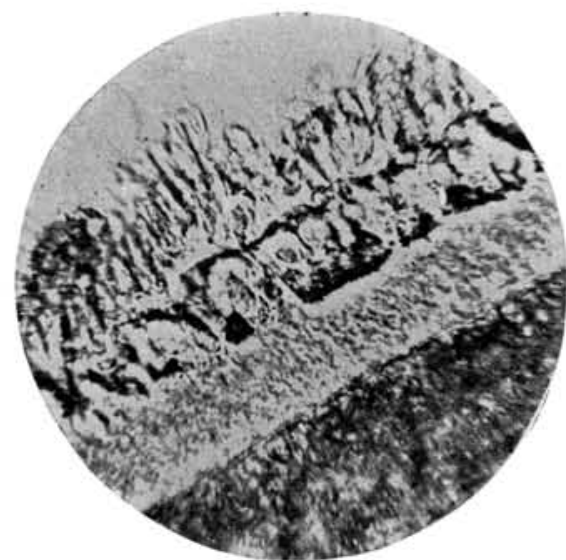

Fis. 16. Calcc-globulin in the Process of Forming a Layer of the Dentine; Also Showing Odontoblasts (High Power) 
That peculiar tissue which we call calco-globulin or the hyaline "tissue on the borderland of calcification," is made up of globular glistening bodies which have coalesced and formed a perfect flow within a gelatinous substance previously given out by the formative cells (fig. 17). It is also the borderland tissue that we find against the dental fibril in the dentine matrix. It is a partially calcified transition tissue, found everywhere between the organic cells that form it, and the calcified matrix which is formed by it. It is the tissue, at this stage - before it fully calcifies--that resists the action

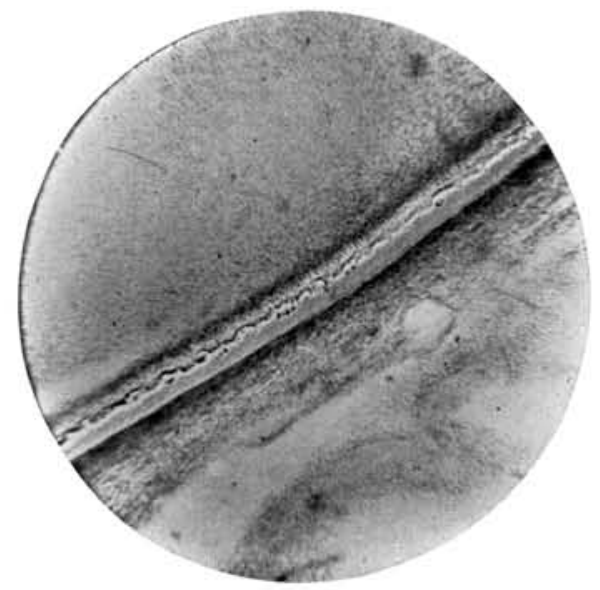

Fig. 17. Layer of Dentine in the Process of Formation, Showing Tissues on the Border Land of Calcification: Hyaline Layer (Low Power)

of acids and caustic alkalis. It is the tissue we find in the lining of the bone cells, the tissue of the so-called sheath of Neumann, and is to be found on every surface where intermembranous bone is developing.

\section{MEMBRANES}

There has been a good deal of confusion in regard to the various tissues found in developing teeth and described as membranes. Most of the earlier investigators, and many of the recent authorities, have told of the many membranes they have found. There is the layer of the formative cells of the dentrice, the odontoblasts, which is called the membrana eboris. The inner and outer layers of the enamel 
organ they call the membrana propria. The stellate reticulum they call the middle membrane, and they have named a horny layer, a substance without a vital function, Nasmyth's membrane. The socalled sheath of Neumann has been called an elastic membrane, when it is but the uncalcified edge of the calcified matrix, surrounding the dentinal fibril. Authorities have stated that the membrana performativa may be found between the enamel cells and the dentine; others say they find it between the enamel cells and the stratum intermedium; and still others will tell you it is found between the odontoblast and the formed dentine.

All this is very confusing. A true membrane may be described briefly as a lamina of vital tissue. It has its part to play in formation, and is to supply its secretions for nourishment to the tissue afterwards. The alveolo-dental periosteum is a very good example of what a real membrane is. It has a vital function. Thin layers of tissue that can be raised from the edge of a calcifying tissue, that stain a little darker than the surrounding tissues, are not membranes. These thin layers have no vital function, and are not vital tissues. The so-called Nasmyth's membrane is not a membrane. It is hornified substance, composed of used up cells from the external stratum intermedium, and of what remains of the ends of the enamel-forming cells after full calcification of the enamel-a layer of waste product wholly, and is entirely destroyed by friction soon after the eruption of the tooth. Klein, in his atlas of histology says of this membrane: "It is the remains of the external epithelium of the enamel organ, and appears to be of the nature of horn." It certainly is not a lamina of vital tissue. The sacculus, surrounding the enamel organ and the dentine germ, is a true vascular membrane, with a future, important, specialized, vital function-a membrane that changes its inner wall to a cement-producing tissue, and its outer wall to the future alveolo-dental periosteum.

\section{"SHEATH OF NEUMANN"}

Professor Hanazawa's article in the Dental Cosmos for February and March, 1917, shows the improbability of the existence of such a tissue in the tooth as the sheath of Neumann. In his presentation of this subject he has given us a carefully prepared and beautifully 
illustrated demonstration; but, while there is every evidence of care in his article, there is very little that is new to us. Over twenty years ago I demonstrated, before many of our societies and associations, that the so-called sheath of Neumann was but a layer of borderland tissue, a transition tissue, the uncalcified edge of the calcified matrix, surrounding the enclosed fiber. I clearly demonstrated that it was not a separate tissue; that it was eventually to become the calcified matrix, as age came on; that, while the tooth was young, it was a borderland tissue (a calco-globulin); and that strong acids or caustic alkalis would cause it to appear to be a separate tissue or sheath, because the wholly calcified matrix would be completely decalcified from it, and thus make it falsely appear to be a sheath. I have stated that the sheath tissue, so-called, calcifies as the tooth grows older and the calibers of canals, by the calcification of a portion of their uncalcified border, have become smaller. Whenever these changes are taking place, the fibrils within the canals probably undergo a change and become hardened into a tissue, resembling borderland tissue. As the tooth ages, the matrix of the dentine becomes less organic. I have a number of sections of old teeth that seem to show this change. The fibrils within their canals seem to be fractured in places, as though calcification had hardened them, and the preparation of the section had fractured them. My investigation was mostly with teeth just erupted, and in these young teeth acid would not destroy the so-called sheath tissue. It was at that time a borderland tissue, or calco-globulin. Acid did destroy the organic fibril, and the whole of the calcified matrix. When the tooth grows old, conditions change, as I have stated. The matrix of the dentine is much less organic; the canals, by gradual calcification of the borderland tissue enclosing the fibers, have become smaller. Borderland tissue has changed to calcified matrix.

The question is asked by Professor Hanazawa about the fluid contents in or about the canals: "Is the flow of the fluid going on simply through the dentinal fibril, as asserted by Romer, or is it carried out through an interstice, which probably exists between the dentine fiber, and the dentinal tubuli?" He probably means the dentinal canal, for there are no tubes in the dentine. The fluid could not pass through the solid fiber; that is certain, and I think he conclu- 
sively proves this by an injection of china ink which he used. The china ink was found to run between the fiber and its wall, just as, twenty years ago, I found the fluid to run when a broken section showed a fiber pulled out of its matrix, with a tiny drop of fluid oozing out between the fiber and its canal.

FNAMEL RODS

Professor Pickerill makes the statement that the single rod of the enamel runs the whole distance from its dentinal end to the surface of the tooth. He finds it twice as wide on the surface of the tooth

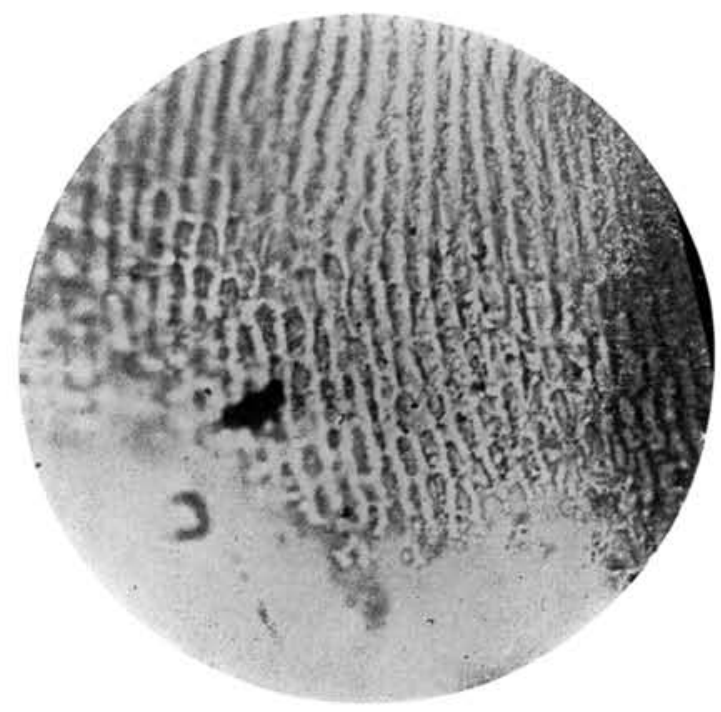

Fig. 18. Enamel Rods Formed from Globular Masses (High Power)

as it is at its junction with the dentine. He states that he has proved this by actual measurement. He also makes this statement: "Supplementary rods, or enamel fibers, are never present to fill out the larger space of its outer surface." Pickerill is in error in this last statement of his. I have seen many supplementary rods in developing enamel. I fail to see how such a statement as Pickerill's could be proven from a section of a fully formed tooth. I have found his last statement to be in error, by actual count, in a section of developing enamel where the rods were forming (fig. 18). It is shown here that cells from the stratum intermedium are being supplied to fur- 
nish new ameloblasts for the regeneration of the larger outer surface. I have, since reading his statement, examined a section of forming enamel; at its dentinal surface I counted nineteen forming rods. I followed up the first of the nineteen to a certain distance, marking it; I then followed up the nineteenth rod to the same distance, marking it, and drew a line across. At the dentinal surface there were nineteen, at the upper line there were twenty-four rods, and one saw clearly where the new rods had entered the forming enamel. This appearance of new rods in process of formation is very evident in many of my sections showing enamel development.

\section{PENETRATING FIBERS IN THE ENAMEL}

Where the cells of the pulp change from connective tissue cells and form a layer of columnar cells, which are the odontoblasts, they are membraneless and little more than masses of protoplasm; when ready to calcify they seem to be filled with great numbers of bright glistening globules of different sizes. It is at this stage of growth that we look for evidence of the penetration of the processes of the fibers of the pear-shaped cells into the as-yet-uncalcified layer of the ameloblasts. And it is at this stage of growth, I would like to impress on your minds, that the enamel organ is fully formed, and the ameloblasts ready to calcify.

The internal epithelium, wholly ameloblasts, the real enamelbuilders, consists of columnar cells, membraneless, and resting on the cusp of the dentine germ. On the outer surface of the dentine germ the connective tissue cells are differentiating into a columnar formation, and these are to be the dentine-matrix builders, soon to begin the process of calcification; for this process takes place first in the odontoblasts until a calcified cap of dentine is formed. After this, the process of calcification takes place in the enamel; but just before calcification we shall find a peculiar layer between these formative cells of the dentine and of the enamel. It is soft and plastic, transparent, and appears to be structureless. Some have called it a zone of amorphous material. Tomes says that it is the formation of the first skin of dentine, a stage of metamorphosis preparatory to the impregnation with calcareous salts. Its formation has originated as 
an exudate from the cells of the dentine germ, and it is formed on its outer surface just before the calcifying process begins. It resembles a borderland tissue.

I have recently been studying this structureless layer, and the condition existing just previous to the formation of a calcified structure, with the desire of ascertaining whether a fiber from a fiber cell can be found to enter enamel tissue. I have found the problem a difficult one from the fact that this structureless layer masks or hides any tissue that may pass into it. We know that the fibers of the fiberforming cells do irregularly enter the enamel (fig. 19). I shall dem-

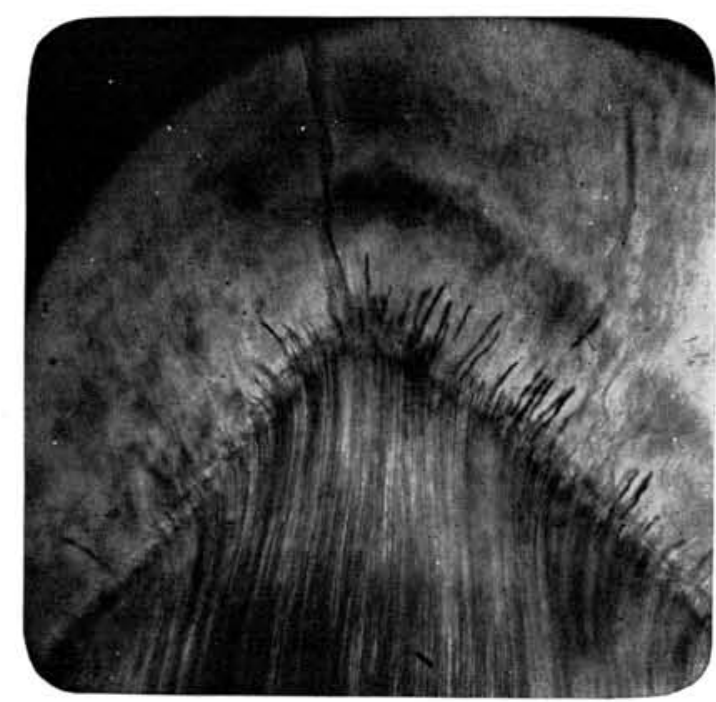

Fig. 19. Penetration of Fibers into Enamel (Low Power)

onstrate that. This may be seen in the crown section of almost any human tooth, and these fibers must have pushed their way into the uncalcified enamel cells at this stage of its development. I have examined many sections just as calcification was about to begin; and I am sure that I have seen the processes of the fiber cells pass into this structureless layer and out on the enamel side, usually in an oblique or irregular line over the ameloblasts in the direction of the stratum intermedium ( fig. 20). I have also teased enamel from the 


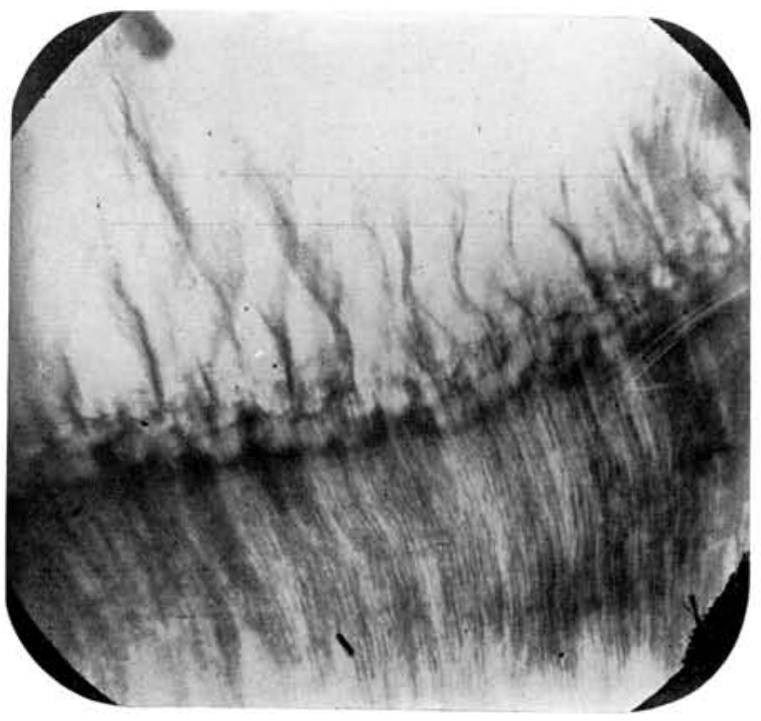

Fig. 20 Penetration of Fibers into Enamel (Low Power)

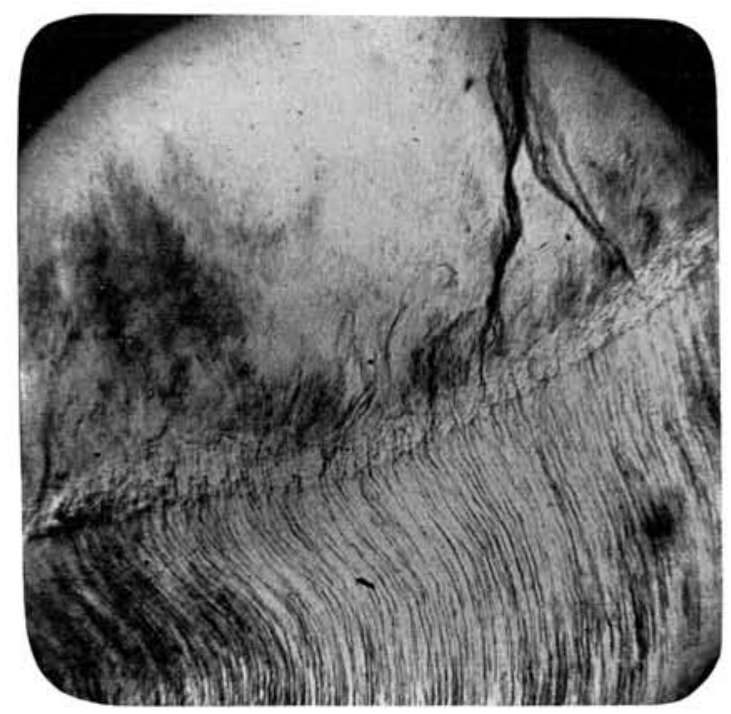

Fig. 21. Penetration of Fibers into Enamel (Low Power) 
dentine at this stage of development, and have seen a few of the fibers from the fiber cells coming through on the outside of the dentinal edge. As a general thing, we expect to see the fibers in the dentine end just before the enamel is reached, but the microscope shows that many of these fibers go entirely through the dentine sections and into the enamel substance ( $f g .21)$. I have a number of sections which show dentine fibers enlarged and flattened by pressure, running nearly through the enamel. Their course is not generally with the direction of the rods. Usually it is an irregular course. Many of the appearances which we have heretofore thought to be cracks in the enamel are really dentinal fibers, which entered the enamel before calcification began, and have become flattened by pressure so as to give them the appearance of cracks, seeming to run nearly to the outer surface of the enamel; and, in several instances, I believe that $I$ have traced them to the outer surface. The cement substance between the enamel rods is a tissue that resembles more nearly a colloid substance than it does a true calco-globulin.

Klein in his atlas of histology states that it is his "opinion that the fibers that penetrate the enamel have their origin from an interglobular space, at the dentinal surface." I am inclined to think this opinion gives us a false interpretation, and for this reason: an interglobular space consists of numerous globular bodies, which are to calcify or have calcified, as globules, into a lifeless exudate, just next to the enamel and cement; often-times interglobular spaces are not found in the crown portion of the tooth. It is possible that fiber cells might become entangled in a space, but a more reasonable explanation would seem to be that a few of the many fiber cells become inverted, or turned about, and send their processes into the as-yetuncalcified layer of enamel cells. In fully calcified enamel, we occasionally find fibers invading that tissue, which are apparently continuous with the fibers that come directly from the dentine matrix.

In my many years of study of the enamel, I have never been able to find a trace of a regular system of living fibers between the enamel rods. With my present knowledge, based on my investigation, I cannot believe that such a system exists. For several years I gave most of my leisure time to investigating this one tissue, trying to 
find fibers, making many hundreds of sections, and treating the tissue with every known method of technic in use at that time, but without results.

\section{SO-CALLED GRANULAR LAYER OF PURKINJI AND OF TOMES}

I propose to try to show that there is no such a layer in the tooth as a granular layer. I am aware that many of our able authors use the term, as many of us used to tell about the "nerve". of the tooth. The human tooth has no nerve. It has a pulp that consists of connective tissue cells, a nerve supply and blood vessels; and this tissue is what remains of the formative pulp, or dentine germ, after calcification. There are many other authors in our profession who tell you about the tubes or tubuli of the dentine, when there are no tubes or tubuli in the human tooth. A tube may be defined as a long cylindrical pipe having an outer, and an inner wall. We do not find pipes in the dentine. What we do find are canals, ducts for the passage of fluids. The canal contains the dental fiber. The wall about it is an uncalcified edge of the calcified matrix, wrongly named the sheath of Neumann.

The layer that is formed near the cementum, on the dentine edge, is not composed of granules. It is a collection of minute calcified globular or mulberry shaped masses, that have failer to make a perfect flow, in forming the first layer of dentine. They have become calcified as globules in the exudate, which has hardened about them. In a section of a root, taken where the first layer of dentine is forming, we see, as I have said, many minute globules being deposited by the odontoblasts into an exudate, a protoplasmic substance which has been given out by the cells. For some reason, probably a form of malnutrition, these globular bodies do not make a perfect flow in the exudate, but calcify as little islands in the exudate, and thus inter-. globular spaces are formed (figs. 22, 23, and 24). They are minute globular bodies, in this location, but they are identical with the large globular bodies we find in the crown of a poorly developed tooth. Among the many thousand crania in the Peabody Museum at Cambridge are skulls of the early Sandwich Islanders. The teeth in these skulls are simply perfect. They are ideal, without fissure or 
flaw of any kind. I have seen such teeth from India. If I could section these teeth, I should not expect to see a trace of this interglobular space, miscalled a granular layer. We are sometimes told that the processes of cement cells anastomose with the processes of the interglobular spaces. This Ibelieve to be in error as I have already explained. They do send their processes through the layer, and do anastomose with the dental canals, but not with the interglobular layer.

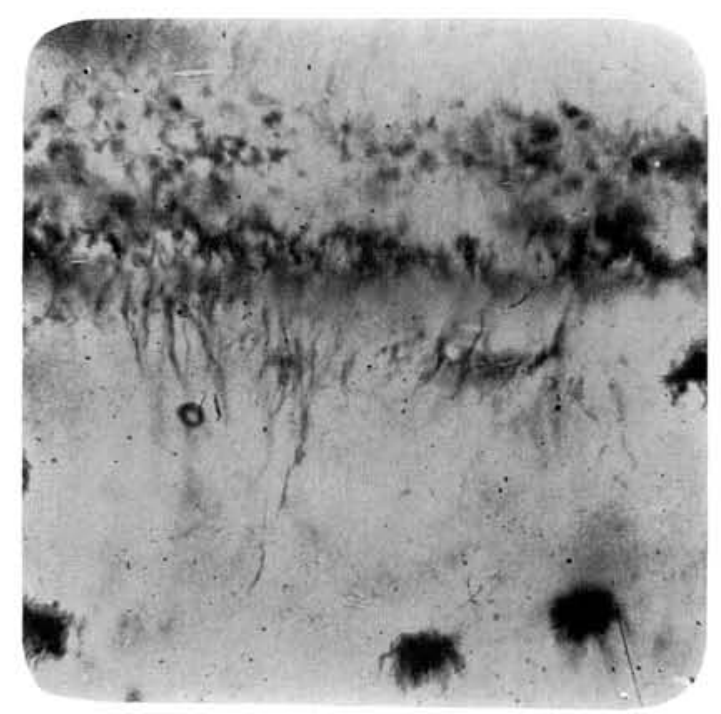

Fig. 22. The So-Called "Granular Layer," A Layer of Interglobular Spaces (High POWER)

NERVE FIBERS WITHIN THE DENTINAL MATRIX

While I was engaged in studying the fiber-forming cell, I saw many indications that led me to believe that very fine nerve fibrils occur between the odontoblasts. I traced them to nerve fibers just within the pulp tissue. I was using at the time (1889) a Zeiss one-twelfth immersion objective, which was loaned to me by Professor Sedgewick, of the Institute of Technology. Wishing to confirm this appearance and trace these nerve fibrils, I made a number of very thin sections, and stained them with an osmic acid stain. 


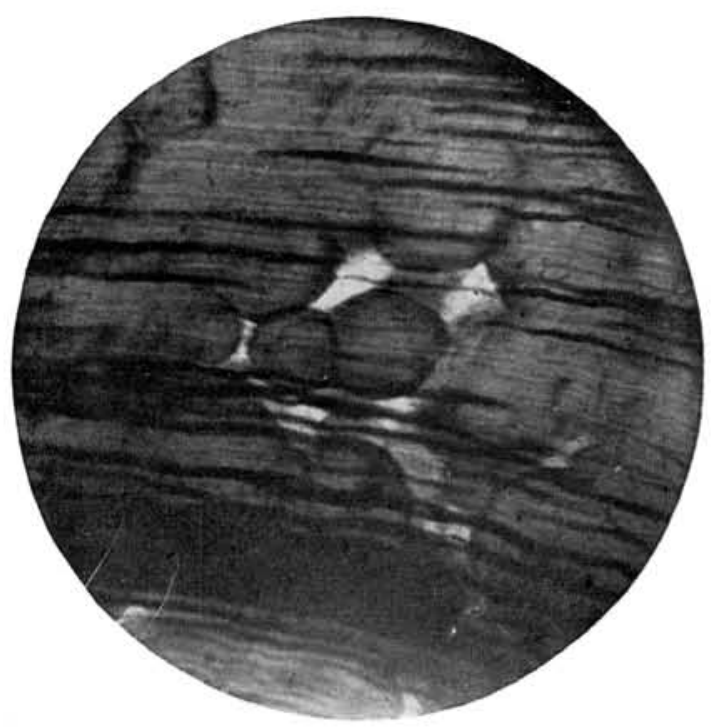

Fig. 23. Interglobular Spaces in Poorly Formed Dentine; Infectid-Prepared by Mitler, Photographed by Andrews (High Power)

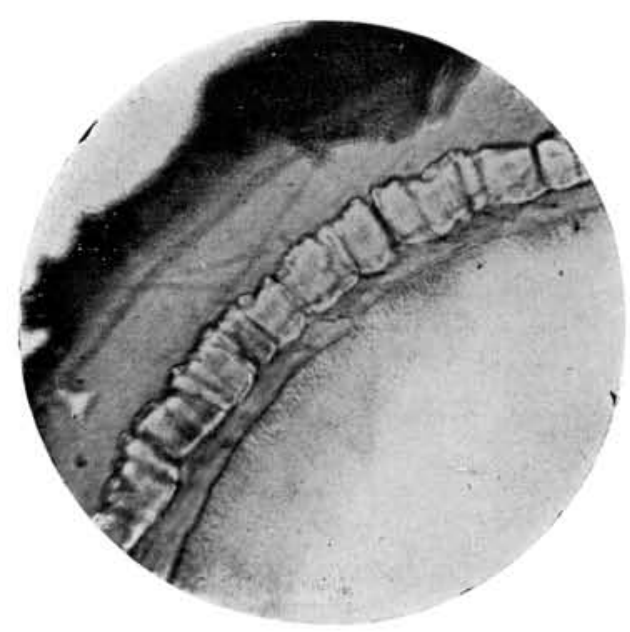

Fig. 24. An Uncalcified Tract in Poorly formed Dentine (Low Power)

TRE JOERNAL OF DENTAL RESEARCH, VOL. I, NO. 3 
The sections showed an extremely delicate and faintly stained filament of nerve tissue, entering the canals and twisting themselves about the dentinal fibrils, for a considerable distance within the dentine. I made several attempts to photograph these appearances, but with the crude instruments of the time, I did not succeed in getting a satisfying or convincing picture. This has been done, however, by Mummery of London, who, a few years ago, before an association in England, demonstrated, by specimen and photograph, the existence of delicate nerve fibrils within the canals of the dentine.

\section{A DISCUSSION OF TALBOT'S OBSERVATIONS}

Talbot has recently published a paper with the title, "Nasmyth's membrane, epithelial débris, and the granular layer of Tomes." Possibly it might be of interest to you if I should briefly point out some of its conclusions, and wherein I differ from them.

I cannot believe the layer of exhausted cells found on the crown of a newly erupted tooth, and called Nasmyth's membrane, is a membrane in any sense. It certainly is not a vital tissue, and it entirely disappears by wear soon after the tooth erupts. It seems to be composed of a substance like horn.

I confess I am at a loss to understand the use of the term "epithelial débris," as used by Talbot. We assume that all are aware that our sections of tissue, shown under the microscope, are of dead tissue, and that we have to use our judgment, as to its appearance in life, from the pictures shown. We certainly see no evidence that normal developing tissue would tolerate "dead cells," within itself. The group of epithelial-cell clusters seen in the illustration in the paper referred to, are living cells that are slowly being absorbed. They are not dead cells as stated. I have seldom seen such clusters of absorbing cells after the tooth is formed, and therefore fail to see how they can be a menace to the health of the surrounding tissue. These epithelial clusters usually wander away towards the stratum malpighi, and are usually absorbed before the tooth erupts. In certain exceptional cases, a cluster of these epithelial cells may excite the embryonic connective tissue to activity and form a papilla, by wandering into the deeper layers, and so form a supernumerary

2 Talbot: Jour. Amer. Med. Assoc., 1918, Ixxi, p. 98 (July 13). 
tooth. This activity in itself would show that these epithelial clusters are not dead.

I also find it somewhat difficult to interpret the structure of several of the sections illustrated in this article, for the reason that the sections fail to show "under high power" even the coarser elements of the structure of the tissue spoken of by the author. In the picture said to be dentine, shown under "a higher power," there are no indications of the existence of the dentinal canals and, in the photograph of the tissue called cementum, there are no indications of cement corpuscles or lacunae. Possibly this vagueness in the illustrations may account for the mistake of calling a few small capillaries, in a newly forming dentine germ, "a nidus of arteries."

The so-called granular layer, which I have shown is not a layer of granules, is stated to be a pathological layer and the seat of most of the troubles of focal infection. I have shown that this is a layer of interglobular spaces that are not pathological. They have been formed by the imperfect flow of the calco-spherites, when the dentine was first forming; but I fail to understand how this layer of interglobular spaces can be a cause of focal infection, except in cases of very marked abnormal development, and then only when they become infected.

There are photographs among the illustrations of Talbot's paper which are all right in themselves, but they have been erroneously interpreted. In one, a considerable amount of root tissue is said to be shown, when the crown has hardly more than commenced to form, all of the tissue of the papilla shown being crown tissue. Another illustration, all right in itself, is said to show that the enamel is normally formed and the tooth about ready to erupt, when the cusp of the future tooth is only commencing to form. One does not find a large enamel organ about a developing tooth when enamel has been normally formed, and the tooth is about to erupt. We see, on the contrary, that the connective tissue and forming alveolus are closing up against the dental follicle and there is no sign of an enamel organ at this period of nearly-finished growth-it has disappeared from the part.

I fear I have wearied you somewhat by the reading of this long paper. The subject is one of great interest to me. In conclusion, I wish to thank you all most sincerely for your close attention. 